удК 336.467

Н. Ю. Ковалевская

Байкальский государственный университет, г. Иркутск, Российская Федерация

В. М. Багинова

Восточно-Сибирский государственный университет технологий и управления, г. Улан-Удэ, Российккая Федерация

\title{
ГОСУДАРСТВЕННОЕ РЕГУЛИРОВАНИЕ КАК ФАКТОР ПОВЫШЕНИЯ КОНКУРЕНТОСПОСОБНОСТИ РЕГИОНА
}

\begin{abstract}
АНнотАЦИЯ. Одним из важнейших факторов, влияющих на экономическую активность и конкурентоспособность в любой сфере экономики, является обеспечение государственных гарантий участникам экономической деятельности. Несмотря на признание представителями различных теорий государства как ключевого участника экономической деятельности, остается дискутируемой идея о необходимости государственного воздействия на интересы других участников деятельности. Наиболее полно все виды интересов субъектов экономической деятельности проявляются на региональном уровне. В связи с этим региональный аспект согласования экономических интересов приобретает особое значение для выбора стратегии социально-экономического развития региона. Одной из перспективных стратегий регионального развития является стратегия создания региональных кластеров как наиболее соответствующая требованиям обеспечения конкурентоспособности региона в условиях глобализации экономики. Для эффективной реализации конкурентных стратегий необходима государственная поддержка процессов кластеризации региона, способствующая их устойчивому развитию.

кЛюЧЕВЫЕ слОВА. Конкурентоспособность региона; экономические интересы; создание региональных кластеров; государственное регулирование.

ИНФОРМАЦИЯ О СТАТЬЕ. Дата поступления 27 октября 2017 г.; дата принятия к печати 19 декабря 2017 г.; дата онлайн-размещения 29 декабря 2017 г.
\end{abstract}

N. Y. Kovalevskaya Baikal State University, Irkutsk, Russian Federation

V. M. Baginova

East Siberian State University of Technology and Management, Ulan-Ude, Russian Federation

\section{GOVERNMENTAL REGULATION AS A FACTOR OF INCREASING REGIONAL COMPETITIVENESS}

\begin{abstract}
One of the most important factors affecting economic activity and competitiveness in any sphere of economy is provision of governmental guarantees to participants in economic activity. Despite the recognition by representatives of various theories of state as a key participant in economic activities, the idea of necessity of the governmental influence on the interests of other participants of activity remains debated. All the types of interests of economic entities are manifested most fully at the regional level. In this regard, the regional aspect of agreement in economic interests acquires a particular importance for selecting the strategy of regional socio-economic development. One of the most promising strategies for the regional development is the strategy of creating regional clusters as the most appropriate one for ensuring the competitiveness of the region in the context of economic globalization. For an effective implementation of the competitive strategies, the state
\end{abstract}

\section{Baikal Research Journal}


support is needed for the regional process of clustering, which contributes to their sustainable development.

KEYWORDS. Competitiveness of region; economic interests; creation of regional clusters; state regulation.

ARTICLE INFO. Received October 27, 2017; accepted December 19, 2017; available online December 29, 2017.

Экономическая активность субъектов хозяйствования и их конкурентоспособность определяется теми условиями, в которых им приходится осуществлять свою деятельность. Одним из важнейших факторов, определяющих эти условия, является наличие государственных гарантий участникам экономической деятельности и защита их прав на федеральном, региональном или муниципальном уровне, что обеспечит поступление денежных средств и в негосударственный сектор экономики, и в национальный бюджет [1].

Одно из самых распространенных представлений о государственном регулировании экономики заключается в необходимости объединения государственных и частных интересов для «...формирования рациональных...соотношений между потреблением, накоплением и инвестированием на основе мер государственного воздействия на рынки инвестиций, подрядных работ, недвижимости» [2]. Происходит это в связи со сменой взглядов на управление региональным инвестиционным комплексом, который уже рассматривается не как иерархическая система, а как система взаимодействия участников экономической деятельности, в которой государство выступает и участником, и регулятором этой деятельности.

Идея необходимости государственного регулирования экономики с признанием главенствующей роли государства разрабатывалась многими классиками экономической науки. Различные экономические школы по-разному представляют роль государства в экономике страны. Классическая экономическая теория, базирующаяся на трудах английских классиков экономической теории, развивала идею абсолютной зависимости всех хозяйственных процессов от действия объективных экономических законов. Согласно кейнсианской концепции рынок не может обеспечить «эффективный спрос», что требует необходимости прямого вмешательства государства в экономические процессы. Согласно неоклассической теории, напротив, государственное вмешательство не должно ограничивать рынок с его естественными саморегуляторами, позволяющими достигнуть экономического равновесия [3].

Как показывают в своей работе Самаруха В.И. и Краснова Т.Г. [4], развитие теории институционализма в дальнейшем стало альтернативой классической и неоклассической экономической теории, поскольку заставило пересмотреть широко распространенный взгляд на саморегулирование экономики, обусловленное совершенством рыночного механизма хозяйствования.

Кемпбелл Р. Макконнелл и Стенли Л. Брю в числе задач государства указывают на необходимость создания нормативно-правовой базы для обеспечения взаимодействия государства и частных структур и создание условий, создающих и поддерживающих конкуренцию. С одной стороны, задача государства как регулятора рынка заключается в формировании внешних условий, т.е. в обеспечении конкурентных условий деятельности хозяйствующих субъектов. С другой стороны, одна из важнейших задач государства - обеспечение экономической безопасности деятельности субъектов хозяйствования. Поэтому государство должно выступать в этом случае и экономическим, и правовым регулятором, посредством влияния на установление равновесной рыночной цены в интересах групп и категорий, поддерживаемых государством, за счет бюджетных ресурсов. Таким образом, признается необходимость учета и согласования интересов экономических субъектов, а противоречия между этими интересами приводят к формированию конкурентной среды.

\section{Baikal Research Journal}

электронный научный журнал Байкальского государственного университета 
Изучение современных публикаций и нормативных документов по этой теме также показывает, что и на федеральном и на региональном уровне, признается первостепенная роль государства. Г.Н. Макарова отмечает, что «в современной экономике институт государства играет не менее значимую роль, чем институты рынка, причем именно характер и состояние данного института по многим параметрам предопределяют возможности эффективного функционирования других институтов и конкретных подсистем и отраслей экономики» [5]. Тем самым признается возрастание значимости роли государства для функционирования национальной экономики и ее развития.

В то же время, акцент на приоритетную роль государства в регулировании экономики не снижает роли предпринимательских и частных (индивидуальных) интересов в развитии ситуации на рынке. Как правило, речь идет о формировании государственно-частных структур, которые, с одной стороны, являются естественными регуляторами рыночных отношений между представителями предпринимательского интереса и государственного, а с другой стороны, обеспечивают эффективное взаимодействие между носителями предпринимательского интереса и частного (индивидуального) интереса (потребителями). Такое взаимодействие властных и бизнес-структур реализуется в форме государственно-частного или муниципально-частного партнерства, заключаемого на определенный срок и основанного на объединении ресурсов и распределении рисков «... в целях привлечения в экономику частных инвестиций, обеспечения органами государственной власти и органами местного самоуправления доступности товаров, работ, услуг и повышения их качества» ${ }^{1}$.

В период перехода на новый этап экономического развития, основанного на инновационных технологиях, происходит усиление процессов глобализации. При этом законы конкуренции становятся определяющими на мировых и отечественных рынках, и только государственное воздействие посредством финансовых и правовых регуляторов может корректировать влияние этих законов.

Зарубежный опыт взаимодействия государства и бизнеса показывает, что хотя поддерживается позиция невмешательства государства, в отношении национальных экономик западные страны активно поддерживают предпринимательские структуры и предпринимательские интересы в наиболее приоритетных секторах экономики. В настоящее время в большинстве западных стран наряду с повышенным вниманием к состоянию малого бизнеса, установилась тенденция к развитию крупных и сверхкрупных компаний. Основной причиной для этого являются условия внешней конкуренции, противостоять которым можно только при наличии государственной поддержки [5]. В отношении внутренней конкуренции государственное регулирование является не менее значимым, учитывая влияние именно представителей интересов крупных предпринимательских структур на экономическую ситуацию. Также прослеживается тесная связь возникновения конкуренции с переделом собственности, происходящим в процессе изменения экономических взаимоотношений участников рынков [6].

Таким образом, регулирующее воздействие государства на экономику предполагает баланс государственных и предпринимательских интересов, поэтому эффективное государственное регулирование должно быть направлено на повышение заинтересованности субъектов рынка.

Вместе с тем, несмотря на усиление роли государства как участника экономических процессов, присущее развитым странам в настоящее время, ведутся споры

${ }^{1}$ О государственно-частном партнерстве, муниципально-частном партнерстве в РФ и внесении изменений в отдельные законодательные акты РФ : закон РФ от 13июля 2015 г. № 224-Ф3 // СПС «Консультант-Плюс».

\section{Baikal Research Journal}

электронный научный журнал Байкальского государственного университета 
по поводу необходимости и степени государственного вмешательства в экономику. Реализация государственных и частных экономических интересов сторон, проявляется в разнообразии форм их взаимодействия. Как было показано ранее [1], в процессе взаимодействия интересов важно не разделять и противопоставлять государственные и частные интересы, а выявлять такие приоритетные стратегические области, в которых интересы государства и интересы частных структур могли бы быть успешно достигнуты. Различные интересы могут проявляться для одних экономических субъектов как цели, в то время как для других они будут выступать в роли ограничений, при этом на уровне региона пересекаются и проявляются все типы экономических интересов собственников (см. рис.).

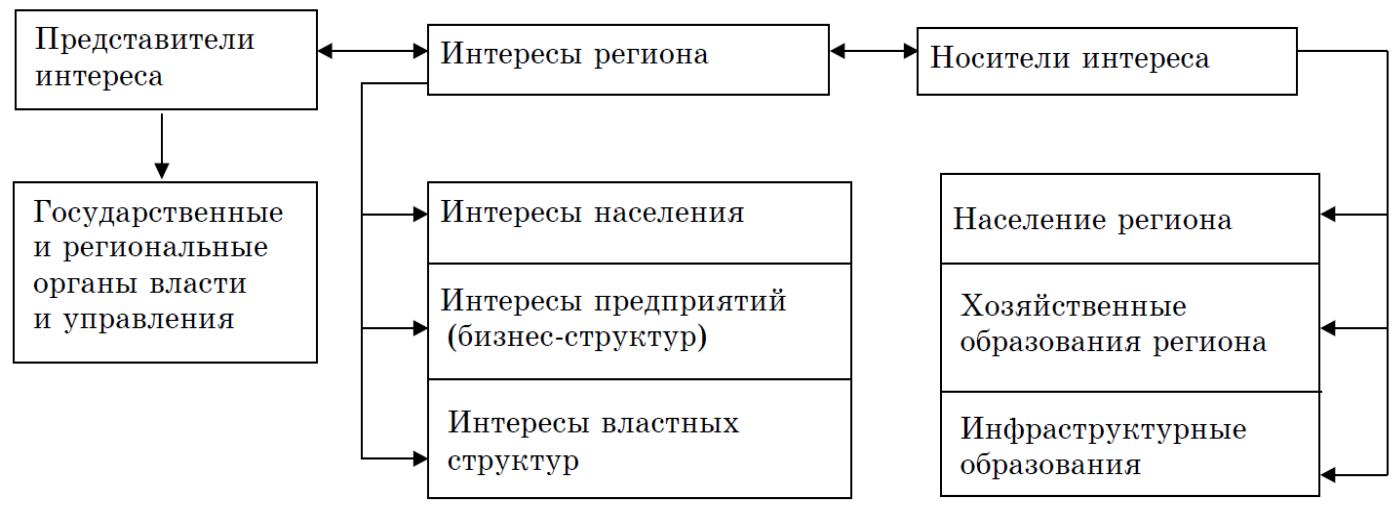

Рис. Взаимодействие интересов различных уровней

Экономические интересы можно определить как «...побудительные мотивы хозяйственной деятельности субъектов территориально-экономической системы, обусловленные их местом в системе отношений собственности и общественного разделения труда» [7]. При этом мотивация деятельности экономических субъектов может быть не только экономического характера. В связи с этим интересы могут быть разделены на:

- политические, направленные на развитии государства или предприятия (организации);

- социальные, отражающие тенденции развития общества;

- индивидуальные интересы, направленные на личное развитие [7].

Все перечисленные виды экономических интересов проявляются на региональном уровне, который можно назвать областью пересечения интересов субъектов экономической деятельности. В связи с этим региональный аспект согласования экономических интересов приобретает особое значение для выбора стратегии социально-экономического развития региона. Согласно одному из определений регион рассматривается как «территориально-отраслевая экономическая система, т.е. определенная упорядоченная совокупность субъектов экономической деятельности, объединенная между собой экономическими и не экономическими интересами» [7].

В современных условиях отмечается изменение роли отдельно взятого региона, обусловленное влиянием глобализации, которое проявляется в т.ч. усилением значения конкурентной позиции, которую занимает субъект на соответствующем уровне экономики, включая макро-, мезо- и микроуровень [8]. При этом в конкурентные процессы оказываются вовлеченными даже те регионы и территории, которые ранее были закрыты таможенными или географическими барьерами. Поэтому регион может рассматриваться как самостоятельный экономический субъ-

\section{Baikal Research Journal}

электронный научный журнал Байкальского государственного университета 
ект, участвующий в конкурентных отношениях как на межрегиональном, так на мировом уровне. Под влиянием этих процессов, по мнению Н.Я. Калюжновой, происходит формирование новых свойств региона как экономической системы, которое проявляется в становлении и развитии такого свойства как конкурентоспособность. При этом под конкурентоспособностью понимается выражение «... потребности сохранения и развития региона как экономического субъекта, функционирующего в условиях конкуренции» [8].

В новых экономических условиях конкурентоспособность региона может рассматриваться как приоритетный фактор его социально-экономического развития, и обеспечивать основу для дальнейшего развития и жизнедеятельности региона. Одним из способов обеспечения конкурентоспособности региона является использование кластерного подхода, обеспечивающего конкурирование и взаимодополнение входящих в него коммерческих и некоммерческих организаций, относящихся к определенной области и объединенных по территориальному принципу. Кластерный подход предполагает развитие промышленности и услуг посредством специализации отдельных географических регионов, что тесно связано с процессами глобализации экономики.

Использование кластерных технологий для повышения конкурентоспособности региональной экономики особенно оправданно в посткризисный период, когда для преодоления последствий кризиса необходим инновационный толчок в развитии. Одна из задач создания кластера заключается в определении приоритетов и защите интересов региональных бизнес-структур как представителей предпринимательских интересов.

Для успешного формирования регионального кластера необходимо согласование стратегии регионального развития и стратегий кластеризации отдельных регионов. Ранее в исследованиях были выделены следующие основные аспекты образования кластера с целью повышения конкурентоспособности региона [9]. Различные аспекты формирования кластера (территориальный, организационно-правовой, социально-экономический) отражают интересы соответствующих групп носителей интереса на уровне региона. Степень реализации регионального экономического интереса конкретной территории, на которой формируется кластер, позволит оценить результативность его создания.

Чаще всего обращают внимание на инвестиционный аспект создания кластеpa, т.е. возможную государственную финансовую поддержку и приток инвестиций в регион, однако, кроме инвестиционного, немаловажную роль играют и ряд других аспектов, способствующих наиболее полной реализации ожиданий участников кластера. Прежде всего, это следующие аспекты.

Теоретический аспект предполагает обоснование его территориальных границ. В этом отношении Байкальский регион является одним из самых благоприятных с точки зрения природных и географических возможностей.

Организационно-правовой аспект предполагает выявление, учет и согласование интересов потенциальных участников кластера, определение организационно-правовых форм их взаимодействия и установление функций участников кластера.

Инновационный аспект связан с проявлением изначальной сущности кластерной формы организации, которую определяет ее инновационная ориентированность. Формирование кластеров происходит, в первую очередь, в тех секторах экономики, в которых возможно или уже осуществляется инновационное развитие техники и технологии производства.

Социально-экономический аспект характеризует степень реализации регионального экономического интереса как совокупности интересов всех экономических субъектов, действующих на территории региона.

\section{Baikal Research Journal}

электронный научный журнал Байкальского государственного университета 
Учитывая перечисленные аспекты, при разработке кластерных стратегий основное внимание направлено в основном на формирование инновационных, туристических, агропромышленных и лесных кластеров, которые в полной мере представлены в Байкальском регионе в соответствии с его природными ресурсами и географическим положением. Причем для Иркутской области, обладающей самым большим лесопромышленным потенциалом в Байкальском регионе и на Дальнем Востоке, одним из приоритетных направлений является формирование и развитие кластеров лесной промышленности. Для Республики Бурятия таким приоритетным направлением является развитие агропромышленного кластера, которое позволит обеспечить конкурентоспособность регионального (республиканского) агропромышленного комплекса и способствовать обеспечения продовольственной безопасности [10].

Следует отметить также высокий рекреационно-туристический потенциал, который имеют оба региона благодаря расположению в регионе уникального природного объекта - озера Байкал. Возможность использования гидроминеральных ресурсов для лечебно-оздоровительных целей позволяет говорить о развитии санаторно-курортного кластера. Кроме того, как отмечается в исследовании Суходолова А. П., «богатейший ресурсный потенциал Байкальского региона позволяет рекреационной деятельности стать одной из базовых отраслей, которая может послужить основой устойчивого социально-экономического развития данной территории» [11].

При этом оба региона имеют свои «плюсы» и «минусы» для реализации кластерной стратегии. Так, для Республики Бурятия в качестве положительных факторов, способствующих формированию агропромышленного кластера, можно назвать благоприятное транспортно-географическое положение, выгодные геополитические условия, обеспечивающие нахождение рядом с регионами с растущим потенциалом (Монголией), большую площадь земель сельскохозяйственного назначения, насыщенность региона природными объектами туристско-экскурсионного значения [12]. К числу отрицательных факторов следует отнести неблагоприятные природно-климатические условия для ведения сельского хозяйства, которые отчасти компенсируются значительной площадью сельскохозяйственных угодий, отчасти образовательными возможностями региона, позволяющими обеспечить кадровую потребность в агропромышленном секторе, а также наблюдаемый в последнее время миграционный отток населения [12].

Поскольку во многом эти факторы могут быть актуальны и для Иркутской области, схема реализации подготовительного этапа создания кластера в любой выбранной отрасли, перспективной с точки зрения инновационного развития, может содержать общие процедуры, указанные в исследованиях на эту тему [13]. К числу таких процедур В. И. Самаруха и Д. А. Иванова относят:

- исследование уровня локализации производства между организациями, образующими кластер;

- анализ матриц межотраслевого баланса;

- изучение технологического уровня производства в отрасли;

- разработка проекта и дорожной карты создания кластера [13].

При создании кластера, как правило, ожидается, что увеличение притока инвестиций послужит стимулом для развития региона, поэтому оценка результативности его функционирования является одним из важнейших аспектов образования кластера. Эта проблема неизбежно возникает, поскольку любая деятельность, в том числе и по созданию кластера может быть рассмотрена как проект, который требует инвестиций для его реализации, а оценка эффективности инвестиций является неотъемлемым этапом оценки результативности деятельности в целом.

\section{Baikal Research Journal}

электронный научный журнал Байкальского государственного университета 
Поскольку речь идет о государственной поддержке создания кластеров, может производиться бюджетная, социальная, экологическая и другие виды оценки.

Бюджетная эффективность создания регионального кластера отражает увеличение доходов за счет производства новых видов продукции или оказания услуг, и как следствие, увеличение налоговых поступлений в региональный (федеральный) бюджет, которые возрастут за счет увеличения налогооблагаемой базы, т.е. развития новых продуктов, предприятий и отраслей [9]

Социальная эффективность отражает регулирующую роль государства в выборе направлений регионального развития и решении задач, первоочередных для данного региона.

Формирование и функционирование кластера предполагает реализацию инвестиционных проектов в тех сферах, которые определены для создания кластера, оценка результативности создания кластера на первоначальном этапе складывается из оценки эффективности инвестиционных проектов, выбранных для реализации кластерной стратегии. Поскольку от реализуемых проектов ожидается эффект на уровне региона и их финансирование может происходить в том числе и за счет средств бюджетов различных уровней, их оценка может производиться аналогично оценке эффективности региональных инвестиционных проектов, реализуемых за счет бюджетных ассигнований. При этом интегральный показатель әффективности инвестиций, направляемых на создание кластера в регионе, будет рассчитан на основе показателей эффективности региональных инвестиционных проектов, рассчитанных в соответствии с «Методикой...»² (табл. 1).

Таблица 1

Показатели әффективности региональных инвестиционных проектов

\begin{tabular}{|c|c|}
\hline $\begin{array}{c}\text { Виды } \\
\text { эффективности }\end{array}$ & $\begin{array}{c}\text { Показатели соответствующего вида эффективности } \\
\text { региональных инвестиционных проектов }\end{array}$ \\
\hline $\begin{array}{l}\text { Экономическая } \\
\text { эффективность }\end{array}$ & $\begin{array}{l}\text { суммарный валовой региональный продукт за период реализации региональ- } \\
\text { ного инвестиционного проекта, полученный в результате его реализации }\end{array}$ \\
\hline $\begin{array}{l}\text { Финансовая } \\
\text { эффективность }\end{array}$ & $\begin{array}{l}\text { чистая текущая стоимость (NPV), внутренняя норма доходности (IRR) } \\
\text { проектов }\end{array}$ \\
\hline $\begin{array}{l}\text { Бюджетная } \\
\text { әффективность }\end{array}$ & $\begin{array}{l}\text { доля дисконтированных налоговых поступлений в бюджеты различных } \\
\text { уровней, полученных в результате реализации региональных проектов, в } \\
\text { общем объеме дисконтированных бюджетных ресурсов за период реализа- } \\
\text { ции проекта }\end{array}$ \\
\hline $\begin{array}{l}\text { Социальная } \\
\text { әффективность }\end{array}$ & $\begin{array}{l}\text { изменение уровня занятости населения в регионе создания кластера за } \\
\text { период реализации проекта; } \\
\text { изменение уровня обеспеченности населения жильем в регионе за период } \\
\text { реализации проекта; доступность и качество услуг населению }\end{array}$ \\
\hline $\begin{array}{l}\text { Экологическая } \\
\text { эффективность }\end{array}$ & $\begin{array}{l}\text { показатели, отражающие изменение состояния окружающей среды за } \\
\text { период реализации регионального инвестиционного проекта }\end{array}$ \\
\hline
\end{tabular}

К числу критериев эффективности регионального инвестиционного проекта следует отнести:

- соответствие регионального инвестиционного проекта стратегии социально-экономического развития региона;

- положительные социальные эффекты от реализации регионального инвестиционного проекта, входящего в стратегию кластеризации;

2 Об утверждении Методики расчета показателей и применения критериев эффективности региональных инвестиционных проектов, претендующих на получение государственной поддержки за счет бюджетных ассигнований Инвестиционного фонда РФ : приказ Минрегионразвития РФ от 30 окт. 2009 г. № 493. URL: https://rg.ru/2010/01/29/metodika-dok.html.

\section{Baikal Research Journal}


- соответствие объема финансирования данного регионального инвестиционного проекта за счет средств регионального бюджета минимальному уровню финансирования проекта,

- соответствие данного проекта критериям финансовой и бюджетной эффективности ${ }^{3}$.

Последовательность применения кластерного подхода в целях повышения конкурентоспособности региона можно представить в виде реализации следующих этапов [9], предполагающих выполнение определенных работ и достижения ожидаемых результатов с учетом отбора региональных инвестиционных проектов для реализации их в сферах, способствующих повышению конкурентоспособности региона (табл. 2).

Таблица 2

Этапы реализации кластерного подхода в регионе

\begin{tabular}{|c|l|l|}
\hline Этап & \multicolumn{1}{|c|}{ Содержание этапа } & \multicolumn{1}{|c|}{ Результат реализации этапа } \\
\hline I этап & $\begin{array}{l}\text { Выбор методики оценки конкурентоспособности } \\
\text { региона; сбор исходных данных и проведение } \\
\text { расчетов }\end{array}$ & $\begin{array}{l}\text { Проведение расчетов в соответ- } \\
\text { ствии с методикой }\end{array}$ \\
\hline II этап & $\begin{array}{l}\text { Выявление факторов, влияющих на конкуренто- } \\
\text { способность региона }\end{array}$ & $\begin{array}{l}\text { Выявление «точек роста» в } \\
\text { регионе }\end{array}$ \\
\hline III этап & $\begin{array}{l}\text { Оценка уровня потенциала кластеризации региона; } \\
\text { Оценка уровня потенциала кластеризации отрасли }\end{array}$ & $\begin{array}{l}\text { Определение этапов стратегии } \\
\text { кластеризации региона }\end{array}$ \\
\hline IV этап & $\begin{array}{l}\text { Оценка региональных инвестиционных проектов, } \\
\text { реализуемых при участии средств регионального } \\
\text { бюджета }\end{array}$ & $\begin{array}{l}\text { Отбор региональных инвестици- } \\
\text { онныхроектов, способствую- } \\
\text { щих формированию кластера в } \\
\text { регионе }\end{array}$ \\
\hline V этап & $\begin{array}{l}\text { Расчет интегрального показателя эффективности } \\
\text { инвестиций, направляемых на реализацию реги- } \\
\text { ональных инвестиционных проектов }\end{array}$ & $\begin{array}{l}\text { Определение бюджетной эффек- } \\
\text { тивнсти }\end{array}$ \\
\hline VI этап & $\begin{array}{l}\text { Расчет показателей оценки конкурентоспособности } \\
\text { региона в соответствии с выбранной методикой; } \\
\text { Оценка влияния кластера на повышение конку- } \\
\text { рентоспособности региона }\end{array}$ & $\begin{array}{l}\text { Определение результативности } \\
\text { формирования кластера и повы- } \\
\text { шение конкурентоспособности } \\
\text { региона }\end{array}$ \\
\hline
\end{tabular}

Использование показателей оценки бюджетной эффективности инвестиций при проведении данных расчетов будет отражать степень государственного участия и влияния на повышение конкурентоспособности региона.

Таким образом, формирование и функционирование кластера способствует повышению конкурентоспособности региона, в интересах региональных органов власти создание на своей территории подобных образований, способствующих усилению регионального экономического интереса и являющихся источниками внутреннего роста и развития региональных экономик. При этом речь идет о формировании механизма согласования отраслевых и региональных экономических интересов, разных хозяйствующих субъектов, функционирующих в пределах конкретной территории и реализуемых в результате создания и развития кластера.

\section{Список использованной литературы}

1. Ковалевская Н. Ю. Инвестиционный аспект государственно-частного партнерства / Н. Ю. Ковалевская // Проблемы экономики и управления строительством в условиях

${ }^{3}$ Об утверждении Методики расчета показателей и применения критериев эффективности региональных инвестиционных проектов, претендующих на получение государственной поддержки за счет бюджетных ассигнований Инвестиционного фонда РФ : приказ Минрегионразвития РФ от 30 окт. 2009 г. № 493. URL: https://rg.ru/2010/01/29/metodika-dok.html

\section{Baikal Research Journal}

электронный научный журнал Байкальского государственного университета 
экологически ориентированного развития: материалы 3-й Всерос. науч.-практ. онлайнконф. 16-17 апр. 2016 г. - Иркутск : Изд-во БГУ, 2016. - С. 239-245.

2. Екимова К. В. Экономические проблемы регионов и отраслевых комплексов [Электронный ресурс] / К. В. Екимова, И. П. Савельева // Проблемы современной экономики. Режим доступа: http: //http://www.m-economy.ru/art.php?nArtId=1132

3. Экономическая теория: учеб. для вузов / под ред. Г. П. ЖЖуравлевой, В. М. Юрьева. Тамбов: Изд-во Тамб. ун-та, 2000. - 757 с.

4. Самаруха В. И. Роль государства в регулировании рыночной экономики / В. И. Самаруха, Т. Г. Краснова // Известия Иркутской государственной экономической академии. - 2004. - № 3 (40). - С. 4-12.

5. Макарова Г. Н. Государственная поддержка крупного предпринимательства реальность экономической политики развитых стран в XXI в. [Электронный ресурс] / Г. Н. Макарова // Baikal Research Journal. - 2012. - № 2. - Режим доступа: http://brjbguep.ru/reader/article.aspx?id=12260.

6. Самаруха В. И. О роли государства в регулировании экономических процессов / В. И. Самаруха // Известия Иркутской государственной экономической академии. 2007. - № 3 (53). - С. 54-57.

7. Багинова В. М. Роль социальной ответственности в сбалансированном развитии региона [Электронный ресурс] / В. М. Багинова, В. А. Рубан // Baikal Research Journal. 2012. - № 6. - Режим доступа: http://brj-bguep.ru/reader/article.aspx?id=16476.

8. Калюжнова Н. Я. Конкурентоспособность российских регионов в условиях глобализации / Н. Я. Калюжнова. - М. : ТЭИС, 2004. - 526 с.

9. Багинова В. М. Кластерный подход в стратегии инновационного развития региона [Электронный ресурс] / В. М. Багинова, А. Г. Николаева // Вестник ТГУ. — 2012. Вып. 3 (107). - Режим доступа: https://cyberleninka.ru/article/n/klasternyy-podhod-vstrategii-innovatsionnogo-razvitiya-regiona.

10. Доржиева Е. В. Определение направлений кластеризации регионального агропромышленного комплекса / Е. В. Доржиева // Известия Иркутской государственной экономической академии. - 2014. - № 5 (97). — С. 90-100.

11. Суходолов А. П. Гидроминеральные рекреационные ресурсы Байкальского региона (бассейна Байкала): характеристика и перспективы использования / А. П. Суходолов // Известия Иркутской государственной экономической академии. - 2014. — № 5 (97). С. $40-46$.

12. Доржиева Е. В. Стратегия развития регионального агропищевого кластера / Е. В. Доржиева // Известия Иркутской государственной экономической академии. 2014. — № 6 (98). - C. 45-53. — DOI: 10.17150/1993-3541.2014.24(6).45-53.

13. Самаруха В. И. Развитие кластерной формы организации производства в лесной промышленности Иркутской области / В. И. Самаруха, Д. А. Иванова // Известия Байкальского государственного университета. — 2016. - Т. 26, № 6. - С. 896-906. DOI: $10.17150 / 2500-2759.2016 .26(6)$. 896-906.

\section{References}

1. Kovalevskaya N. Yu. Investment aspect of public-private partnership. Problemy ekonomiki $i$ upravleniya stroitel'stvom $v$ usloviyakh ekologicheski orientirovannogo razvitiya : materialy 3 Vseros. nauch.-prakt. onlain-konf. 16-17 apr. 2016 g. [Problems of Economy and Construction Management in Terms of Ecologically Oriented Development. Materials of 3-d All-Russian Science and Practice Online Conference, April 16-17, 2016]. Irkutsk, Baikal State University Publ., 2016. pp. 239-245. (In Russian).

2. Ekimova K. V., Savel'eva I. P. Economic problems of regions and industrial complexes. Problemy sovremennoi ekonomiki = Problems of modern economics. Available at: http: //http://www.m-economy.ru/art.php?nArtId=1132. (In Russian).

3. Zhuravleva G. P., Yur'ev V. M. (eds.) Ekonomicheskaya teoriya [Economic theory]. Tambov, State University Publ., 2000. 757 p.

4. Samarukha V. I. Krasnova T. G. The role of a state in market economy management. Izvestiya Irkutskoi gosudarstvennoi ekonomicheskoi akademii = Izvestiya of Irkutsk State Economics Academy. 2004, no. 3 (40), pp. 4-12. (In Russian).

\section{Baikal Research Journal}


5. Makarova G. N. Government support of large business - reality of economic policy of the developed countries in the xxi century. Baikal Research Journal, 2012, no. 2. Available at: http://brj-bguep.ru/reader/article.aspx?id=12260 (In Russian).

6. Samarukha V. I. The role of state in economic process regulation. Izvestiya Irkutskoi gosudarstvennoi ekonomicheskoi akademii = Izvestiya of Irkutsk State Economics Academy, 2007, no. 3 (53), pp. 54-57. (In Russian).

7. Baginova V. M., Ruban V. A. Role of social responsibility in sustainable development of the region. Baikal Research Journal, 2012, no. 6. Available at: http://brj-bguep.ru/reader/ article.aspx?id=16476 (In Russian).

8. Kalyuzhnova N. Ya. Konkurentosposobnost' rossiiskikh regionov $v$ usloviyakh globalizat sii [Competitiveness of Russian regions in terms of globalization]. Moscow, TEIS Publ., 2004. $526 \mathrm{p}$.

9. Baginova V. M. The cluster Approach in Innovative Regional Development Strategy. Vestnik Tomskogo gosudarstvennogo universiteta = Tomsk State University Journal, 2012. Vol. 3 (107). Available at: https://cyberleninka.ru/article/n/klasternyy-podhod-v-strategii-innovatsionnogo-razvitiya-regiona_(In Russian).

10. Dorzhieva E. V. Determining the directions of the region's agricultural complex clusterization. Izvestiya Irkutskoi gosudarstvennoi ekonomicheskoi akademii = Izvestiya of Irkutsk State Economics Academy, 2014, no. 5 (97), pp. 90-100. (In Russian).

11. Sukhodolov A. P Hydro mineral recreational resources of the Baikal region (Baikal basin): characteristics and prospects of usage. Izvestiya Irkutskoi gosudarstvennoi ekonomicheskoi akademii = Izvestiya of Irkutsk State Economics Academy, 2014, no. 5 (97), pp. 40-46. (In Russian).

12. Dorzhieva E. V. The strategy of the regional agro-food cluster development. Izvestiya Irkutskoi gosudarstvennoi ekonomicheskoi akademii = Izvestiya of Irkutsk State Economics Academy, 2014, no. 6 (98), pp. 45-53. DOI: 10.17150/1993-3541.2014.24(6). (In Russian).

13. Samarukha V. I., Ivanova D. A. The development of the cluster forms of production organization in the forest industry of the Irkutsk region. Izvestiya Baikal'skogo gosudarstvennogo universiteta $=$ Bulletin of Baikal State University, 2016, vol. 26, no 6, 896-906. DOI: 10.17150/2500-2759.2016.26(6).896-906. (In Russian).

\section{Информация об авторах}

Ковалевская Наталья Юрьевна - кандидат экономических наук, доцент, кафедра экономики и управления инвестициями и недвижимостью, Байкальский государственный университет, 664003, г. Иркутск, ул. Ленина, 11, e-mail: kovalevskayanu@bgu.ru.

Багинова Виктория Матвеевна - доктор экономических наук, профессор, кафедра бухгалтерский учет, анализ и аудит, Восточно-Сибирский государственный университет технологий и управления, 670013, г. Улан-Удэ, ул. Ключевская, 40б, e-mail: baginova_v@ mail.ru.

\section{Authors}

Natalya Yu. Kovalevskaya - PhD in Economics, Associate Professor, Chair of Economics and Investment and Real Estate Management, Baikal State University, 11 Lenin St, 664003, Irkutsk; e-mail: kovalevskayanu@bgu.ru.

Viktoriya M. Baginova - Doctor habil. In Economics, Professor, Chair of Accounting, Analysis and Audit, East-Siberian State University of Technologies and Management, 406 Klyuchesvskaya St., 670013, Ulan-Ude; e-mail: baginova_v@mail.ru

\section{Для цитирования}

Ковалевская Н. Ю. Государственное регулирование как фактор повышения конкурентоспособности региона / Н. Ю. Ковалевская, В. М. Багинова // Baikal Research Journal. 2017. — T. 8, № 4. - DOI : 10.17150/2411-6262.2017.8(4).15.

\section{For Citation}

Kovalevskaya N. Y., Baginova V. M. Governmental regulation as a factor of increasing regional competitiveness. Baikal Research Journal, 2017, vol. 8, no. 4. DOI: 10.17150/24116262.2017.8(4).15. (In Russian).

\section{Baikal Research Journal}

